\title{
Towards a pre-teen typology of digital media
}

\author{
Mick Grimley and Mary Allan \\ University of Canterbury
}

\begin{abstract}
Whilst prior research has identified children as avid users of new technologies, insufficient studies have explored their patterns of use. This paper investigates how New Zealand pre-teens use technology out of school and identifies a typology of technology use. Two hundred and twenty four children between 10 and 12 years of age completed a comprehensive questionnaire about their use of technology. Results indicated that children of this age were immersed in technology related activities. A principal components factor analysis revealed a typology with five distinct factors underlying pre-teen digital behaviour. Two factors showed some differentiation by gender but differences were not evident for socio-economic factors.
\end{abstract}

\section{Introduction}

Seventy two percent of American adults report being online daily (Lenhart et al, 2008) and children report even higher usage (Livingstone \& Bober, 2004; Lenhart, Madden \& Hitlin, 2005). Media use and its effect on children has long been debated, but within the last twenty years the proliferation of new digital media and the immersion of children and young adults in its use has created a very different landscape with Generation Z (Wellner, 2000; Geck, 2006) portrayed as thinking, behaving and learning differently from previous generations (Donaldson, 2006; Feiertag \& Berge, 2008; Prensky, 2001; Robinson, 2007; Tapscott, 1999). Generation Z are labeled digital natives to distinguish them from digital immigrants who were introduced to digital technologies later in their lives (Prensky, 2001). This distinction led to the perception that all those born after 1980 belong to one homogeneous group of digitally immersed experts in all that is digital. Selwyn (2009; p2) observes that:

These simplified understandings remain influential in shaping contemporary public, political and academic expectations of the technological capabilities and demands of those children and young people who were 'digitally born' in the late twentieth and early twenty-first centuries.

The difference between digital natives and digital immigrants is often attributed to the immersion in digital technologies and the availability and access to information (Geck, 2006). Studies show that the human brain is malleable and that a person's environment can shape and change cognitive processes (Nisbett, 2001; O'Boyle, 1998). Educational technologists in agreement with this concept argue that the extensive digitally immersed environment surrounding the younger generation has altered their cognitive processing, thus making them think, act and learn differently (Prensky, 2009; 2001; Oblinger, 2004). This concept shifts the focus from the technology to its use and users and raises the possibility that digital natives, like other generations, may not be a homogenous group. 
The homogeneity of the digital natives is challenged in studies showing that highly contented students report less media use and low contented children report more music and video game exposure. High sensation seeking students spend more time watching TV and listening to music, with exposure to media being positively correlated with sensation seeking behaviour. In addition, high users of technology are more likely to spend time with friends and family and partake in other hobbies (Roberts, Foehr \& Rideout, 2005).

There is little knowledge about how digital immersion affects people, especially how it affects their educational experiences (Bennett, Maton \& Kervin, 2008). Livingstone and Bober (2004) suggest that daily users of the Internet have much to gain and are more likely to use diverse forms of digital media. Studies of digital media engagement by children and teens tend to focus on risks and benefits. Positive and negative outcomes of increased computer use on children and teens have been reported, ranging from the risk of obesity and antisocial behaviour to improved academic performance (Subrahmanyam, Kraut, Greenfield \& Gross, 2000).

The link between academic performance and digital media has been investigated primarily for school activities, linking digital media proficiency and attitudes to its application in school work (Arafeh, Levin, Rainie \& Lenhart, 2002). These authors found that Internet savvy students use the Internet to help them with their school work, and are aware of various aspects in which the Internet can support their school work. Furthermore, they found that students' perceptions of the use of the Internet in school enables them to translate traditional school tasks to Internet activities and tools (Arafeh, Levin, Rainie \& Lenhart, 2002). Other studies such as that by Roberts, Foehr and Rideout, (2005) investigated the correlation between exposure to certain media and academic achievements, suggesting that students' grades were positively related to print media exposure but were negatively linked to playing computer games.

Having reviewed these studies, we propose that for digital media use to be effective in schools there is a need to move away from the paradigm that perceives digital natives as a homogenous group, and to uncover typologies of digital media use. It is anticipated that the identification of the different typologies will contribute to the effective use of digital media for learning. In view of the pervasiveness of digital media in contexts outside school, we argue that to discover the typologies of digital natives there is a need to study their interaction with digital media beyond the school context.

This study argues that there are different typologies within the group defined as digital natives and propose to identify these typologies by investigating differences in the use of digital media. The study follows digital natives of different socio-economic backgrounds to identify possible differences in use relating to the level of assets accessible. This defining factor has been proposed in Horrigan's (Horrigan, 2007, 2009) longitudinal studies of ICT typologies.

\section{A review of typologies}

Studies of adults' use of digital media usually focus on accessibility and application. Horrigan $(2007,2009)$ based his longitudinal study of digital media use on three key aspects:

1. Assets - accessibility of gadgets and services

2. Actions - activities involving the use of digital media 
3. Attitudes - perceptions of digital media in the lives of users.

Horrigan's typology proposes ten groups that fit broadly into "high user," "medium user," and "low level adopter" categories. The groups within each broad category have their own particular characteristics, attitudes and usage patterns. Elite users have the highest access to ICTs, are heavy and frequent users and, to varying degrees, are engaged in user-generated content. Members of these groups have generally high levels of satisfaction about the role of ICTs in their lives, but the groups differ by whether extra availability is good or not. "Middle of the road" users consist of two groups whose views of ICTs are task oriented. They use ICTs for communication more than they use it for self-expression. One group finds this pattern of information technology use satisfying and beneficial, while the other finds it burdensome. Groups with few technology assets (four groups) view modern gadgetry as at or near the periphery of their daily lives. Some find it useful, others don't, and others are satisfied with using the telephone and television (Horrigan, 2007). Horrigan's work implies that typologies can be defined according to levels of use, and type of use. Implied in his typologies are three types of engagements with digital media: creation, connectedness, and use of content.

\section{Factors contributing to typologies}

A number of factors are likely to contribute to a digital media typology including:

- Technology exposure - digital natives have been exposed to digital technology from birth and are more likely to have a different typology of technology use than the general population (Prensky, 2001).

- Cognitive factors - Freese, Rivas and Hargittai (2005) suggest that a person's use of technology is partly mediated by cognitive factors especially given the intellectual nature of many digital activities and internet resources.

- Socio-economic factors - Bosah (1998) suggests that socio economic and education factors affect the choice of technologies. His work suggests that audiovisual technologies are in relatively high use in the lower education and socio economic groups, and are mainly associated with the consumption of content, mainly for entertainment. However, the use of ICT in higher levels of education and socio economic status is attuned to the production as well as consumption of content, and that in this group ICT is more often associated with work and study related activities. The preferred ICTs in this group are those which offer not only consumption but also production of content (Allan, 2007).

\section{Method}

\section{Participants}

Two hundred and twenty four participants (139 male, 85 female) aged 10-12 years from the New Zealand Canterbury region completed a digital immersion questionnaire. Participants were recruited from 10 primary schools representing a wide range of socio-economic populations depicted in Table 1. New Zealand schools are graded on a scale of 1-10 called decile rating that depicts the extent to which a school draws its students from low socio-economic communities. Decile 1 schools are the $10 \%$ of schools with the highest proportion of students from low socio-economic 
communities. Decile 10 schools are the $10 \%$ of schools with the lowest proportion of these students. In order to compare high decile students with low decile students the current sample was split into Low Decile: 1-6; High Decile: 7-10. To comply with ethical practices, 6th year students were provided with information letters and consent forms to be signed by their parents. Only students who returned signed consent forms were included in the sample.

Table 1: Study sample size and decile distribution

\begin{tabular}{|l|c|c|}
\hline \multicolumn{1}{|c|}{ School } & Decile rating & Sample $\mathrm{n}$ \\
\hline School A & 3 & 14 \\
\hline School B & 6 & 27 \\
\hline School C & 10 & 30 \\
\hline School D & 2 & 11 \\
\hline School E & 10 & 35 \\
\hline School F & 10 & 37 \\
\hline School G & 6 & 12 \\
\hline School H & 6 & 25 \\
\hline School I & 5 & 8 \\
\hline School J & 10 & 25 \\
\hline Total & & 224 \\
\hline
\end{tabular}

\section{Materials}

A comprehensive questionnaire was designed to survey the type and extent of digital behaviour that students were engaged in. The questionnaire included 3 scales asking about different aspects of children's technology use:

1. A list of 14 items asking respondents about home access to digital hardware (Table 2). Respondents were required to answer yes/no/don't know.

2. A list of 16 items asking respondents about leisure time activities undertaken during the last 7 days (Table 3). Respondents placed a cross in a box if they had undertaken a particular activity in the last 7 days.

3. A list of 28 digital activities asking respondents to indicate how often they perform different digital activities by indicating; never, sometimes, often or all the time (Table 4).

\section{Procedure}

Ten primary schools agreed to take part in the project and year 6 teachers in each school were informed of the procedure and purpose of the research. All year 6 (10$12 \mathrm{yrs}$ ) children in each school were given information to describe the research and parent/guardians and students were asked to complete consent forms. Students who returned completed forms were included in the project and asked to complete the immersion questionnaire. Instructions on questionnaire completion were given by the researcher to all participants. Questionnaires were completed, between June and August 2007, in class, with the help of the teacher and the researcher (if required). No time limits were placed on participants and the researcher checked all questionnaires on collection. 


\section{Results and discussion}

\section{Description of out of school digital media use}

Table 2 shows the extent to which participants had access to different technologies at home. Examination of this data indicates that participants had good access to computers with only $6 \%$ indicating otherwise. High decile students reported greater access and more high decile students indicated that they had access to broadband compared to low decile students (low $=28 \%$, high $=48 \%$ ). Unsurprisingly, most students indicated that they had access to a TV and DVD/video player. In addition, $83 \%$ had access to a mobile phone with only a $4 \%$ difference between high and low decile groups. However, although most mobile phones are equipped with MP3 players, games, digital cameras and digital video cameras, these devices were reported as being much less accessible than mobile phones. Furthermore, high decile participants reported greater access to digital still cameras, digital video cameras and MP3 players compared to low decile participants. It appears that mobile phones are seen as distinct technology devices and not necessarily bundles of technology (hand-held games, MP3 players and cameras) housed within the same device. The overall statistics in Table 2 suggest that students in the sample had good access to digital technologies with only slightly better access overall for high decile students. These results suggest that the digital divide in terms of access to digital devices is not so prominent for younger populations.

Table 2: Access to technology as a percentage socio-economic status

\begin{tabular}{|l|c|c|}
\hline \multicolumn{1}{|c|}{ Students with home access to technology } & Low decile & High decile \\
\hline Computer & 88.7 & 98.4 \\
\hline Computer with dial up & 61.5 & 62.2 \\
\hline Computer with broadband & 28.4 & 48.4 \\
\hline DVD/video & 100 & 98.4 \\
\hline TV & 99 & 96.9 \\
\hline Game console & 69.1 & 67.2 \\
\hline Hand-held game & 45.4 & 47.2 \\
\hline Audio system & 55.7 & 72.2 \\
\hline MP3 player & 35.1 & 60.5 \\
\hline CD Walkman & 57.7 & 65.1 \\
\hline Digital still camera & 67.0 & 87.2 \\
\hline Digital video camera & 42.3 & 56.5 \\
\hline PDA & 2.1 & 6.5 \\
\hline Mobile phone & 81.3 & 85.0 \\
\hline
\end{tabular}

Figure 1 depicts the different after school activities students engage in during a typical week. The questionnaire asked students to describe their activities in the past 7 days. The results show that pre-teen children are typically engaged in many different activities and these include digital as well as traditional activities, such as reading a book and spending time with friends. This concurs with other reports that suggest that increased time spent on digital activities does not necessarily mean a decrease of more traditional activities (Roberts, Foehr \& Rideout, 2005). Further, the highest levels of technology related after school activities are associated with the consumption of content: $95.0 \%$ watched TV, $91.5 \%$ listened to music. However, high decile students reported a higher incidence of reading a book for pleasure and engagement in after school activities compared to low decile students. The graph also reveals a slightly higher level of use of digital media for consumption of content in the lower decile 
schools. However, the 'use of computer' implying the ability to generate content is similar for both decile levels. This finding may indicate a difference in choice of content creation versus content consumption in different socio economic groups (Bosah, 1998). Further, digital activities for low decile students overall seemed to be greater than for high decile students (e.g. use of a mobile, play computer games, listen to music digitally) suggesting that increased access to digital devices for low decile students may be beneficial in that it provides additional outlets during leisure time.

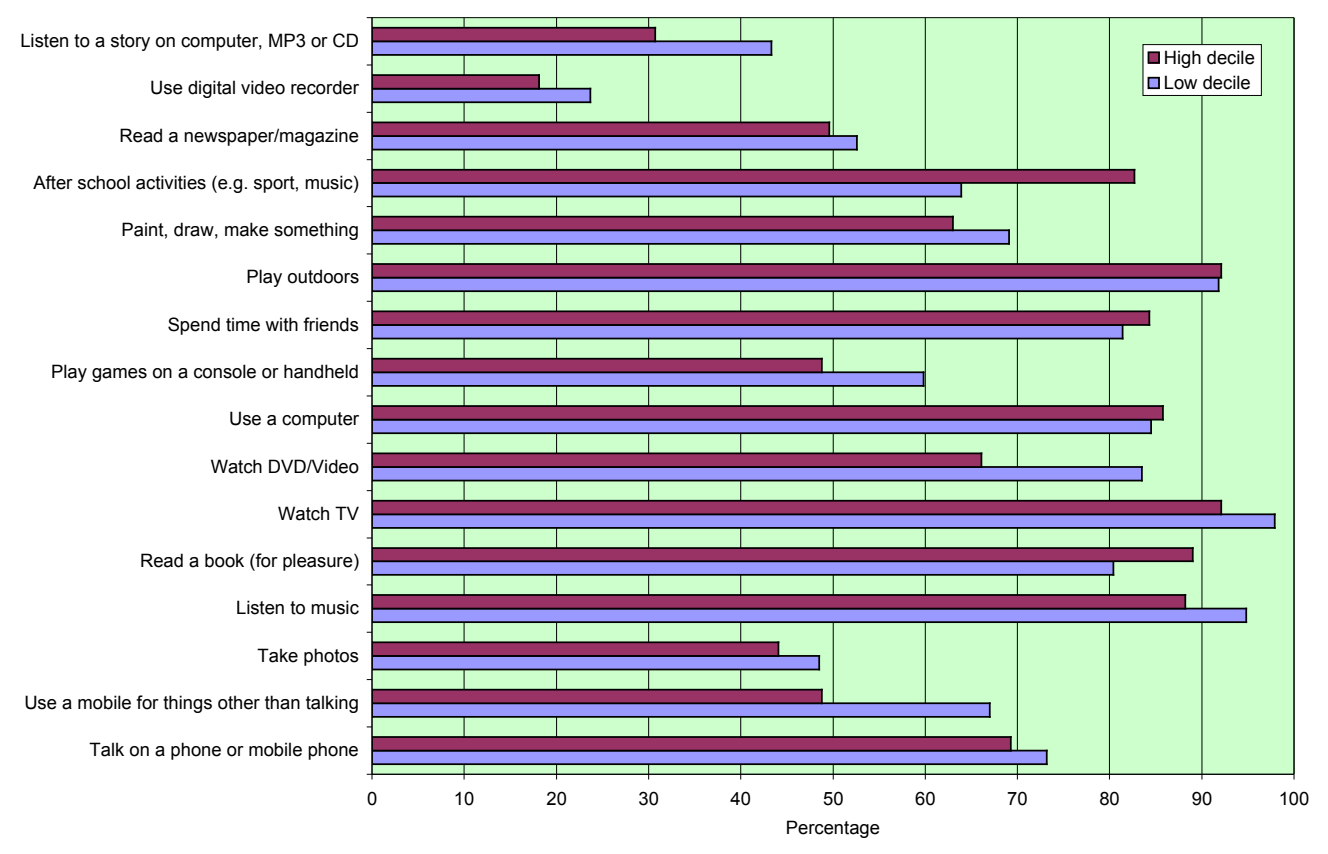

Figure 1: After school activities undertaken in the last 7 days as a percentage of socio-economic status

Table 3 shows the extent to which participants engaged in a variety of after school digital activities ranging from the more advanced creative activities such as blogging, podcasting, and composing music, to more basic activities such as emailing and creating documents. These were calculated for both high decile and low decile students and show a range of usage frequencies including those who never use such technologies, those participants that sometimes use such technologies and those that use them often or all of the time. The table also differentiates the use of technology into consumption of content, communication activities and creation activities. In clustering the activities into consumption and creation categories we attempt to discover whether Bosah's (Bosah, 1998) distinction of activities between high and low socio economic status apply to digital natives. The data shows no significant difference, although a slightly higher activity in low decile high use compared with high decile high use for communication and creation can be detected which may suggest that as technology permeates into low socio-economic households the usage gap is beginning to ameliorate. In addition, the findings align with the Roberts, Foehr and Rideout (2005) study of 8-18 year olds which reports digital media as having a pervasive influence on students' out of school activities. 
Table 3: Level of use for different digital activities as a percentage, differentiated by decile rating

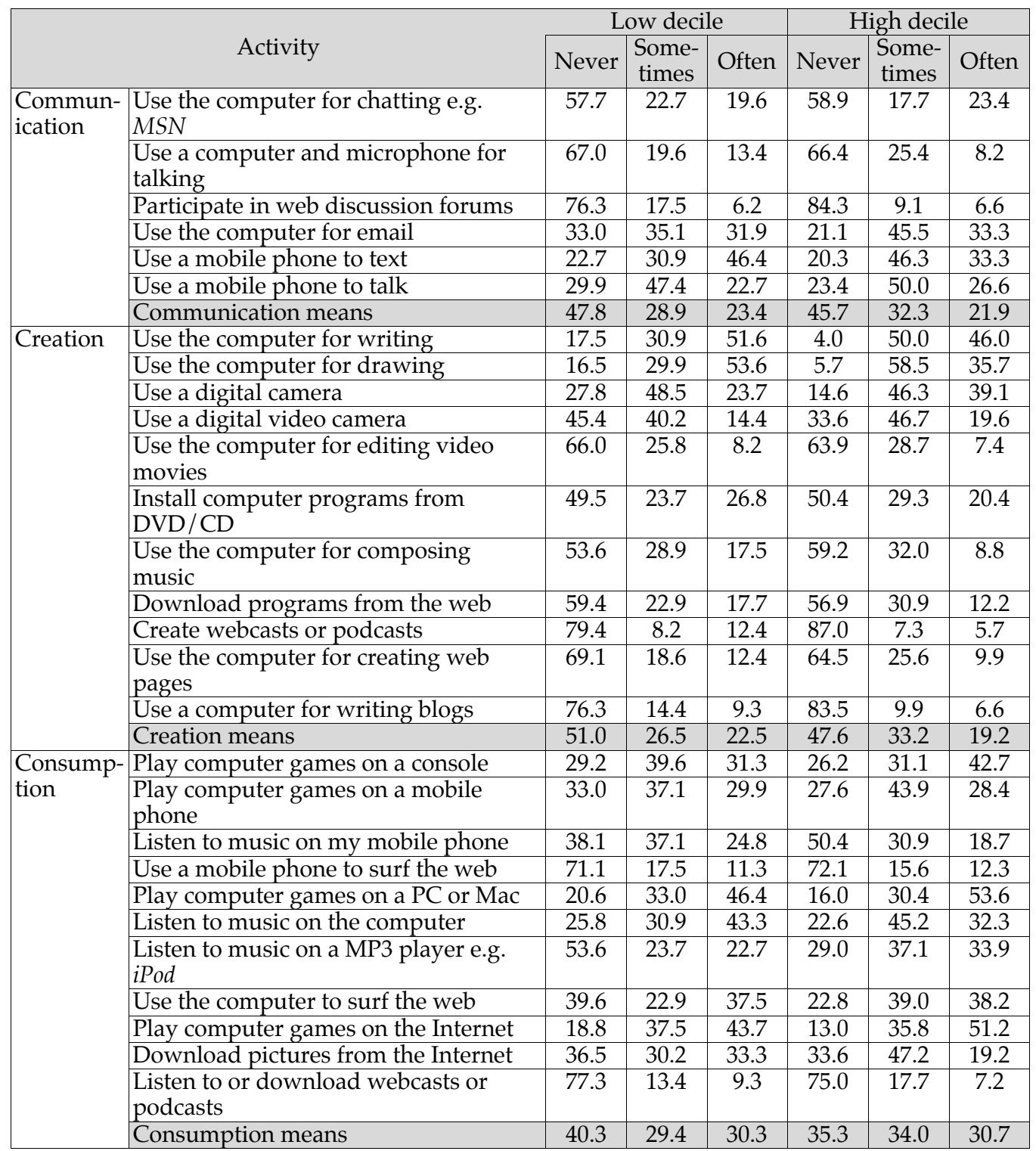

In order to explore the types of digital activity that tend to cluster together to describe different groups of digital users a principal components factor analysis with oblique rotation and Kaiser normalisation was performed on the 28 items used to describe the frequency of engagement in different digital leisure time activities (see Table 5). An oblique rotation was used as resulting factors were expected to be correlated, due to participants of one digital activity also being likely to engage in other digital activities.

The data was scrutinised to ensure that it was of sufficient quality for a principal components factor analysis to be conducted. A correlation matrix of all 28 items 
established that each item correlated above .3 with at least one other item and that no two items were correlated above .7. The determinant of the correlation matrix was found to be greater than 0.00001 indicating no multicollinearity. The Kaiser-MeyerOlkin measure of sampling adequacy was confirmed as .86 and therefore above the recommended value of .5 and Bartlett's test of sphericity was significant (Chi squared $(378)=2214.24, p<.001)$. Finally, diagonals of the anti-image correlation matrix were all above .5, supporting the inclusion of all 28 items.

An initial analysis set the cut off for eigen values above 1 and indicated a six factor solution. However, after examination of the scree plot, a $\mathrm{N}$ value below 250 and a number of communalities below .7 it was decided to accept only 5 factors. The analysis was repeated for a 5 factor model with factor loadings below .4 being suppressed. All 28 items were retained and loaded onto 5 factors. All items had primary loadings over .5 except for item 5 which had a primary loading of .43. The factor loading matrix for this final solution is presented in Table 4.

Table 4: Factor loadings

\begin{tabular}{|c|c|c|c|c|c|}
\hline & $\begin{array}{l}\text { Web } \\
\text { presence } \\
\text { and } \\
\text { resources }\end{array}$ & $\begin{array}{c}\text { Standard } \\
\text { use: } \\
\text { games, } \\
\text { music, } \\
\text { email }\end{array}$ & $\begin{array}{l}\text { Mobile } \\
\text { phones }\end{array}$ & $\begin{array}{l}\text { Basic } \\
\text { docu- } \\
\text { ment pro- } \\
\text { duction }\end{array}$ & $\begin{array}{c}\text { Creating } \\
\text { multimedia: } \\
\text { music, } \\
\text { sound, } \\
\text { vision }\end{array}$ \\
\hline Use a computer for writing blogs & 748 & & & & \\
\hline Create webcasts or podcasts & .729 & & & & \\
\hline $\begin{array}{l}\text { Listen to or download webcasts or } \\
\text { podcasts }\end{array}$ & .706 & & & & .481 \\
\hline Use the computer for creating web pages & 699 & & & & \\
\hline Download pictures from the Internet & .677 & & & & \\
\hline Use the computer for chatting e.g. MSN & .645 & 436 & & & \\
\hline $\begin{array}{l}\text { Use a computer and microphone for } \\
\text { talking }\end{array}$ & .635 & & & & \\
\hline Download programs from the web & .633 & .462 & & & .513 \\
\hline Participate in web discussion forums & .595 & & & & \\
\hline Use the computer to surf the web & & .736 & & & \\
\hline Play computer games on the Internet & & .711 & & & \\
\hline Use the computer for email & & .663 & & & \\
\hline Play computer games on a PC or Mac & & .619 & & & \\
\hline Listen to music on the computer & & .563 & & & .416 \\
\hline Listen to music on a MP3 player e.g. iPod & & .433 & & & .423 \\
\hline Use a mobile phone to text & & & .824 & & \\
\hline Use a mobile phone to talk & & & .789 & & \\
\hline Listen to music on my mobile phone & & & .717 & & \\
\hline Use a mobile phone to surf the web & & & 684 & & \\
\hline Play computer games on a mobile phone & & & .535 & & \\
\hline Use the computer for writing & & & & .823 & \\
\hline Use the computer for drawing & & & & .793 & \\
\hline Use a digital camera & & & & & .712 \\
\hline Use a digital video camera & & & & & .698 \\
\hline $\begin{array}{l}\text { Use the computer for editing video } \\
\text { movies }\end{array}$ & & & & & .684 \\
\hline $\begin{array}{l}\text { Install computer programs from } \\
\text { DVD/CD }\end{array}$ & .454 & & & & .593 \\
\hline Use the computer for composing music & 448 & & & & .534 \\
\hline Play computer games on a console & & .435 & & & .507 \\
\hline
\end{tabular}


Amalgamated mean scores created for each factor based on the mean of the items with their primary loadings on each factor show the level of participation for each factor (final column Table 5). 'Very basic document production' is the activity students reported doing the most $(\mathrm{M}=1.55, \mathrm{SD}=.77)$, closely followed by 'standard computer use: games, music, email' $(\mathrm{M}=1.28, \mathrm{SD}=.74)$. In addition, the component correlation matrix shows moderate correlations between each factor (Table 5).

Table 5: Means and SD of digital activity scores for each factor and component correlation matrix

\begin{tabular}{|l|c|c|c|c|c|c|}
\hline & $\begin{array}{c}\text { Web } \\
\text { pres- } \\
\text { ence }\end{array}$ & $\begin{array}{c}\text { Standard } \\
\text { computer use: } \\
\text { games, music, } \\
\text { email }\end{array}$ & $\begin{array}{c}\text { Mobile } \\
\text { phones }\end{array}$ & $\begin{array}{c}\text { Very basic } \\
\text { document } \\
\text { produc- } \\
\text { tion }\end{array}$ & $\begin{array}{c}\text { Creating } \\
\text { multimedia: } \\
\text { music, sound, } \\
\text { vision }\end{array}$ & $\begin{array}{c}\text { Means } \\
\text { and } \\
\text { standard } \\
\text { deviations }\end{array}$ \\
\hline $\begin{array}{l}\text { Web presence and } \\
\text { resources }\end{array}$ & 1.00 & .21 & .19 & .10 & .36 & $.51(.58)$ \\
\hline $\begin{array}{l}\text { Standard computer use: } \\
\text { games, music, email }\end{array}$ & .21 & 1.00 & .21 & .12 & .33 & $1.28(.65)$ \\
\hline Mobile phones & .19 & .21 & 1.00 & .08 & .26 & $.96(.67)$ \\
\hline $\begin{array}{l}\text { Very basic document } \\
\text { production }\end{array}$ & .10 & .12 & .08 & 1.00 & .07 & $1.55(.84)$ \\
\hline $\begin{array}{l}\text { Creating multimedia: } \\
\text { music, sound, vision }\end{array}$ & .36 & .33 & .26 & .07 & 1.00 & $.85(.57)$ \\
\hline
\end{tabular}

The factor analysis revealed a typology of 5 categories of children's digital technology use:

1. A 'Web presence and resources' category aligned with 9 digital activities including; writing blogs, creating podcasts, creating web pages, downloading pictures, listening to podcasts, chatting over the web using the computer, chatting using a computer with audio, downloading programs and taking part in web discussions. This group appears to be driven by creating a presence on the web for themselves and communicating with others of a similar nature and retrieving web resources such as graphics and programs and is akin to the 'Elite users', or the 'Digital Collaborators' group identified by Horrigan $(2007,2009)$.

2. The 'Standard computer use: games, music, email' factor aligned with 6 activity items including; surfing the web, playing games on the net, email, playing games on a PC or Mac, listening to music on a computer and listening to music on a MP3 player. Although this group does not correlate well with any of the groups identified by Horrigan (2009), it is reasonable to identify a group of 10-12 year olds who frequently surf the web, play games and listen to music. This kind of digital technology use is supported by Roberts, Foehr and Rideout (2005) reporting a large proportion of 8-18 year olds who play games and listen to music digitally.

3. The 'Mobile phones' category included 5 activities all related to mobile phone use; texting, talking, surfing, games and music. This factor is somewhat similar to the 'Roving Nodes' and 'Mobile Newbies' groups identified by Horrigan (2009) but appears to be more mobile phone centric.

4. The 'Very basic document production' category mainly used the computer for drawing and writing and aligned with just 2 items; use of the computer for drawing and use of the computer for writing. It is likely that this group is less tech savvy than other groups. Table 3 shows that both low and high decile groups of 
students report high percentages of using the computer for drawing and writing compared to other digital activities. This likely represents the basic use of computers for writing and drawing now demonstrated by many students compared to non digital methods. Also this is likely to reflect the increase in the use of computers for school assignments. However it is notable that low decile participants showed elevated levels of never using the computer for such purposes compared to high decile participants. The reason for this is unclear but may reflect the desire for low decile students to engage in more interactive computer use.

5. The 'Creating multimedia: music, sound, vision' aligned with 6 activity items; using digital cameras, using digital video cameras, editing movies, installing computer programs from disc, composing music and playing computer games on a console. This group appeared to enjoy manipulating and experiencing multimedia content. It is unclear whether they also like to share content with others but if so would be akin to the 'media movers' group reported by Horrigan (2009).

Thus, these five categories represent distinct types of users that seem to be present for 10-12 year olds. Two groups of users are engaging in more sophisticated activities such as creating multimedia or creating a web presence through more advanced digital manipulations. Two groups of users seem to be using digital resources for the more basic day to day activities such as drawing or writing using a computer, or playing games, emailing and listening to music digitally. A fifth group is predisposed with the mobile phone.

\section{Exploration of digital behaviour by gender and decile grouping}

In order to explore the results of the immersion questionnaire by gender and socio economic status a MANOVA was calculated using decile group (high deciles 2-6; low deciles 7-10) and gender (male, female) as independent variables and the 5 activity factors as dependant variables. Results indicate a main effect of gender $(\mathrm{F}=4.64, \mathrm{df}=5$, $213, \mathrm{p}<0.0001$ ) showing that males reported higher overall usage of technology (male mean and $\mathrm{SD}=26.3$ (13.3), female mean and $\mathrm{SD}=23.5$ (12.1), Cohen's $\mathrm{d}=.22$ ). These main gender differences can be explained by gender differences for 'Web presence' ( $\mathrm{F}=4.64$, $\mathrm{df}=5,213, \mathrm{p}<0.0001$; male=.57 (.65), female=.42(.43); Cohen's $\mathrm{d}=.28)$ and 'Creating multimedia: music, sound, vision' $(\mathrm{F}=4.64, \mathrm{df}=5,213, \mathrm{p}<0.0001$; male $=.95$ (0.60), female=.69 (0.49); Cohen's $\mathrm{d}=.48$ ) both showed more activity for males, but had low effect sizes. These gender differences are small in comparison to the extent to which pre-teens are taking up the use of technology in their leisure time. Female use of technology for three of the five factors appear to be equal with only small differences favouring boys for 'creating multimedia' and 'web presence' which are perhaps the more 'geeky' digital activities compared to the other categories. No decile differences were observed for any of the five factors perhaps indicating that previously reported socio-economic differences in technology use (digital divide) are diminishing as previously suggested by Livingstone and Helsper (2007), and that differences in technology use patterns are now better predicted by cognitive factors as suggested by Freese, Rivas and Hargittai (2006).

\section{Conclusion}

The study confirms that pre-teen users of digital technology have good access to different digital technologies and are engaged in a variety of digital activities, some complex, others more basic. Their digital activity appears to be described by a 
typology that is similar to that of adults because it suggests that the primary factor creating different groups is the level and type of use of the technology rather than its availability. School decile does not appear to have a significant effect on engagement with digital media. Low decile school children with slightly lower access to technology report similar levels of use to those reported by high decile students. This suggests that the ubiquity of technology and levels of access do not necessarily result in higher use. Bosah's theory of higher socio-economic groups as more engaged in the creation of content is not significantly apparent in this sample. However, the study population here is pre-teens, and the difference between creation and consumption may appear at a more mature age.

The gender factor shows a small effect favouring boys for activities such as creating multimedia content and creating a web presence, which are among the more ambitious uses of the technology. However, the bigger picture seems to suggest that pre-teen males and females are integrally involved in digital activities during leisure time. Further research as to why these differences occur is warranted.

This preliminary investigation into the digital behaviour patterns of pre-teens reiterates the notion that the abundant presence of technology will not necessarily result in increased levels of use, and that other factors need to be considered (Allan, 2009; Allan \& Thorns, 2008). Further research is warranted that explores how different digital behaviour patterns might affect the development of cognitive behaviour in school aged children, and how the implementation of digital activities within school might mediate educational outcomes for different types of digital users. This is essential if we are to establish effective educational interventions. In addition, there is a need for educationalists to explore patterns of technology use displayed by children and to identify factors that determine such patterns of use, because children's use of technology will affect how they approach educational tasks and the subsequent outcomes of these tasks. Increased use of digital technology outside of the classroom, especially for students previously disadvantaged socially, may be leveraged to improve educational opportunities if digital technologies are used appropriately within schools, but more work in this area is warranted. The fact that this study indicates that low socio-economic students choose to perform creative digital activities equally if not more so than high socio-economic status students suggests that schools should be taking advantage of this for in school digital activities rather than perpetuating an impoverished curriculum for low socio-economic students as suggested by a number of sources (Muller, Sancho \& Hernandez, 2009).

Ubiquitous learning (u-learning), for example, takes advantage of new mobile technologies to support and extend the learning of children in school by "providing the right content for the right learners, at the right time, in the right place and in the right context" (Tsai, Tsai \& Hwang, 2010). Such use of technology may align well with 'mobile' learners but more studies are needed to make the connections between the use of technology and the user profiles. Thus, more research is required to investigate the impact that aligning teaching in schools with students' digital activities would have on student learning outcomes. For instance, students who play computer games outside of school could be given activities that align with this, such as game design activities, or the teacher could use computer games to stimulate interest in a particular area of the curriculum.

Digital creation activities could be utilised to enhance student learning for those who fall into the 'Creating multimedia: music, sound, vision' category. This research 
indicates a propensity for pre-teens to read and write using digital technology at home. Therefore it would be wise for schools to utilise this natural inclination through the use of blogs and other such communication tools (Tse, Yuen, Loh, Lam \& Ng, 2010). It is becoming particularly important for schools to consider the interests and inclinations of students outside of school when designing learning activities and more research in this area is essential.

Finally, the current study although carried out across a number of schools of varying decile ratings is limited by a relatively small sample and does not include participants from the lowest decile rated schools. Further research in this area is warranted with a need for a much larger national or international sample covering all decile levels. As technology permeates society, with the body of digital natives increasing, knowledge of how users use technology in their leisure time and how this relates to education will become increasingly important.

\section{Acknowledgments}

We would like to formerly acknowledge the help and support given by Dr Richard Riding in writing this paper, his advice, as usual, was invaluable. In addition, this research could not have taken place without funding provided by the College of Arts Research Committee at the University of Canterbury, we are very grateful.

\section{References}

Allan, M. (2007). Millennial teachers: Student teachers as users of information and communication technologies. International Journal of Education and Development using ICT, 3(2), 16-29. http: / /ijedict.dec.uwi.edu / viewarticle.php?id=286

Allan, M. (2009). Sustainable collaborative research activities: A system's approach to the implementation of e- conferencing for lower carbon footprint (Research report). Christchurch: Social Science Research Centre - University of Canterbury. http: / / ir.canterbury.ac.nz/ handle/10092/3623

Allan, M. \& Thorns, D. (2008). A methodological quest for studying interactions in advanced video conferencing environments. Paper presented at the 4th International Conference on eSocial Science, Manchester UK, June 18-20. http: / / hdl.handle.net/ 10092/ 732

Bennett, S., Maton, K. \& Kervin, L. (2008). The 'digital natives' debate: A critical review of the evidence. British Journal of Educational Technology, 39(5), 775-786.

Bosah, E. L. (Ed.) (1998). Cyberghetto or cybertopia? Race, class, and gender on the Internet. Praeger: Westport, Conn.

Donaldson, C. (2006). The Millennials are here! PNLA Quarterly, 71(1), 21-26. [a version is available at http:/ / works.bepress.com/christy_donaldson/11, verified 2 Jun 2010]

Feiertag, J. \& Berge, Z. L. (2008). Training Generation N: How educators should approach the Net Generation. Education \& Training, 50(6), 457-464.

Freese, J., Rivas, S. \& Hargittai, E. (2006). Cognitive ability and Internet use among older adults. Poetics, 34, 236-249. [verified 2 Jun 2010] http:/ / www.jeremyfreese.com/docs/FreeseRivasHargittai\%20-\%20CogAbNetUseOlderAdults.pdf

Geck, C. (2006). The Generation Z connection: Teaching information literacy to the newest Net Generation. Teacher Librarian, 33(3), 19-23. 
Horrigan, J. (2007). A typology of information and communication technology users. (Research report) Washington, DC: Pew Internet \& American Life Project. [verified 2 Jun 2010] http: / / www.pewinternet.org/Reports / 2007 / A-Typology-of-Information-andCommunication-Technology-Users.aspx

Horrigan, J. (2009). The mobile difference. (Research report). Washington, DC: Pew Internet \& American Life Project. [verified 2 Jun 2010] http:/ / www.pewinternet.org/Reports / 2009/5The-Mobile-Difference--Typology.aspx

Lenhart, A., Madden, M. \& Hitlin, P. (2005). Teens and technology. (Research report). Washington DC: Pew Internet \& American Life Project. [verified 2 Jun 2010] http: / / www.pewinternet.org/Reports/2005/Teens-and-Technology.aspx

Lenhart, A., Kahne, J., Middaugh, E., Macgill, A., Evans, C. \& Vitak, J. (2008). Teens, video games, and civics. (Research report). Pew Internet and American Life Project. [verified 2 Jun 2010] http: / / www.pewinternet.org/Reports / 2008/Teens-Video-Games-and-Civics.aspx

Arafeh, S., Levin, D., Rainie, L. \& Lenhart, A. (2002). The Digital Disconnect: The widening gap between Internet-savoy students and their schools. Washington, DC: Pew Internet \& American Life Project. [verified 2 Jun 2010] http: / / www.pewinternet.org/Reports / 2002/ The-DigitalDisconnect-The-widening-gap-between-Internetsavvy-students-and-their-schools.aspx

Livingstone, S. \& Bober, M. (2004). Taking up online opportunities? Children's use of the Internet for education, communication and participation. E-Learning, 1(3), 395-419.

Livingston, S. \& Helsper, E. (2007). Gradations in digital inclusion: Children, young people and the digital divide. New Media and Society, 9(4), 671-696.

Muller, J., Sancho, J. M. \& Hernandez, F. (2009). New media literacy and the digital divide. In L. Tan Wee Hin \& R. Subramaniam (Eds), Handbook of research on new media literacy at the K-12 level: Issues and challenges Volume 1. Information Science Reference: Hershey, PA.

Nisbett, R. E., Peng, K., Choi, I. \& Norenzayan, A. (2001). Culture and systems of thought: Holistic versus analytic cognition. Psychological Review, 108(2), 291-310.

Oblinger, D. (2004). The next generation of educational engagement. Journal of Interactive Media in Education, 8. Special Issue on the Educational Semantic Web. http: / /wwwjime.open.ac.uk/2004/8/oblinger-2004-8.pdf [viewed 6 Nov 2009, verified 2 Jun 2010].

O'Boyle, M. W. \& Gill, H. S. (1998). On the relevance of research findings in cognitive neuroscience to educational practice. Educational Psychology Review, 10(4), 397-409.

Prensky, M. (2001). Digital natives, digital immigrants. On the Horizon, 9(5). http: / / www.marcprensky.com/writing/Prensky\%20$\%$ 20Digital $\%$ 20Natives, $\%$ 20Digital\%20Immigrants $\% 20-\%$ 20Part1.pdf

Prensky, M. (2009). H. sapiens digital: From digital immigrants and digital natives to digital wisdom. Innovate, 5(3). http:/ / www.innovateonline.info/index.php?view=article\&id=705 [viewed 4 Nov 2009, verified 2 Jun 2010].

Roberts, D. F., Foehr, U. G. \& Rideout, V. (2005). Generation M: Media in the lives of 8-18 year-olds. Report for the Henry J. Kaiser Family Foundation (Menlo Park, CA, The Henry J. Kaiser Family Foundation). [verified 2 Jun 2010; 3.3 MB] http: / / www.kff.org/entmedia/ upload/ Generation-M-Media-in-the-Lives-of-8-18-Year-olds-Report.pdf

Robinson, M. (2007). Digital nature and digital nurture: Libraries, learning and the digital native. Library Management, 29(1/2), 67-76. 
Selwyn, N. (2009). The digital native - myth and reality. Invited presentation to the Chartered Institute of Library and Information Professionals. London, 10 March 2009. [viewed 5 Nov 2009, verified 2 Jun 2010] http:/ / www.scribd.com/doc/9775892/Digital-Native

Subrahmanyam, K., Kraut, R. E., Greenfield, P. M. \& Gross, E. F. (2000). The impact of home computer use on children's activities and development. Children and Computer Technology, 10(2), 123-144.

Tapscott, D. (1999). Growing up digital. New York: McGraw-Hill.

Tsai, P. S., Tsai, C. C. \& Hwang, G. H. (2010). Elementary school students' attitudes and selfefficacy of using PDAs in a ubiquitous learning context. Australasian Journal of Educational Technology, 26(3), 297-308. http:/ / www.ascilite.org.au/ajet/ajet26/tsai.html

Tse, S. K., Yuen, A. H. K., Loh, E. K. Y., Lam, J. W. I. \& Ng, R. H. W. (2010). The impact of blogging on Hong Kong primary school students' bilingual reading literacy. Australasian Journal of Educational Technology, 26(2), 164-179.

http: / / www.ascilite.org.au/ajet/ajet26/tse.html

Wellner, A. S. (2000). Generation Z. American Demographics, September, 61-64.

Dr Mick Grimley, School of Education Studies and Human Development,

University of Canterbury, New Zealand. Email: michael.grimley@canterbury.ac.nz

Web: http:/ / www.eshd.canterbury.ac.nz/ people/grimley.shtml

Dr Mary Allan, School of Social and Political Sciences, University of Canterbury,

New Zealand. Email: mary.allan@canterbury.ac.nz

Web: http: / / www.saps.canterbury.ac.nz/people/mallan.shtml 